\title{
Value of external quality assessment of the technical aspects of histopathology
}

\author{
WT BARR, ED WILLIAMS* \\ From the Department of Histopathology, University Hospital of Wales, Heath Park, Cardiff, SWales, CF4 $4 X W$ \\ and the ${ }^{*}$ Department of Pathology, Welsh National School of Medicine, Heath Park, Cardiff, CF4 4XN
}

SUMMARY An external quality assessment scheme (EQAS) in the technical aspects of histopathology is described, and the results obtained over a two-year period assessed. The scheme involved 42 laboratories of varied work load, and the slides returned by the laboratories, both haematoxylin and eosin and special stains: were marked by panels of four assessors. The reliability of assessment was checked by comparing the results of two separate panels of assessors, and by asking the same panel to assess the same set of slides on a different occasion. The participants' evaluation of the scheme was tested by questionnaire.

The results show that the scheme described was considered to be of value by the great majority of the participants. The assessment of the slides by a panel was shown to be both reliable and reproducible. We believe that a general application of schemes such as the one described will maintain and improve standards in histopathology laboratories.

External technical quality assessment poses many more problems in histopathology than in other branches of pathology, largely because the assessment is subjective rather than numerate. It has been shown previously that external quality assessment (EQA) is applicable to histopathology in a small scheme in a restricted area. ${ }^{1}$ We now report results obtained from a much larger trial of EQA over a two-year period. We hoped in this trial to determine:

(a) whether the marking of the quality of sections by a panel of assessors was reliable and reproducible.

(b) the acceptability of EQA to histopathology laboratories chosen at random.

(c) the efficiency of the organisation of the scheme.

(d) the value of participation to the laboratories.

\section{The scheme}

PARTICIPATING LABORATORIES

English histopathology laboratories were categorised as having low, medium or high work loads $(<4000$, $4000-8000$, and $>8000$ requests per annum). One laboratory was chosen at random from each of these categories from each of 14 regional health authorities and invitations to participate were sent to the chief medical laboratory scientific officer (MLSO) and consultant pathologist in each department.

Accepted for publication 10 June 1982
Thirty-eight of the 42 departments invited accepted the invitations, two declined and two did not reply. Four reserve departments accepted their invitations, so completing the required number for the trial. Participation was voluntary and confidential.

\section{MATERIAL CIRCULATED}

For 20 months, each department was sent a fixed block of tissue monthly except for one month when serial sections were sent. The blocks for any month were taken from the same specimen and were as closely similar as possible. The departments were asked to treat the assessment block in the same way as their routine surgical biopsy specimens. They were asked to return stained slides, usually both a haematoxylin and eosin ( $\mathrm{H}$ and $\mathrm{E})$ and a special staining technique, to the organisers by a specified date. The time allowed was not more than three weeks. The specimens and stains requested are shown in Tables 1 and 2.

\section{ASSESSMENT}

Each slide was marked by four assessors. During the first year of the scheme the slides were sent to a second (control) panel of four assessors, to enable comparison of the consistency of assessment to be carried out.

Because of the numbers involved, the laboratories 
Table 1 Material circulated for quality assessment and the group mean scores (first year of scheme)

\begin{tabular}{|c|c|c|c|c|c|}
\hline \multirow{2}{*}{$\begin{array}{l}\text { Circulation } \\
\text { No }\end{array}$} & \multirow[t]{2}{*}{ Tissue } & \multirow[t]{2}{*}{ Presentation } & \multirow[t]{2}{*}{ Request } & \multicolumn{2}{|c|}{ Group mean scores } \\
\hline & & & & $\begin{array}{l}\text { North } \\
\text { Labs }\end{array}$ & $\begin{array}{l}\text { South } \\
\text { Labs }\end{array}$ \\
\hline 1 & Liver & Block in formol saline & (a) $\mathrm{H}$ and $\mathrm{E}$ & $9 \cdot 5$ & $10 \cdot 6$ \\
\hline 2 & Stomach & Block in formol saline & $\begin{array}{l}\text { (a) } \mathrm{H} \text { and } \mathrm{E} \\
\text { b) } \mathrm{PAS} \text { with haematoxylin counterstain }\end{array}$ & $\begin{array}{r}10 \cdot 1 \\
9.5 \\
9.1\end{array}$ & $\begin{array}{l}10 \cdot 1 \\
10 \cdot 3 \\
10 \cdot 4\end{array}$ \\
\hline 3 & Spleen & Block in buffered formalin & $\begin{array}{l}\text { (a) } \mathrm{H} \text { and } \mathrm{E} \\
\text { (b) Giemsa }\end{array}$ & $\begin{array}{l}9 \cdot 2 \\
6 \cdot 8\end{array}$ & $\begin{array}{r}10 \cdot 5 \\
9 \cdot 4\end{array}$ \\
\hline 4 & Artery & Block in formol saline & $\begin{array}{l}\text { (a) } \mathrm{H} \text { and } \mathrm{E} \\
\text { (b) Elastic/van Gieson (resorcin fuchsin type) }\end{array}$ & $\begin{array}{l}9 \cdot 2 \\
8 \cdot 0\end{array}$ & $\begin{array}{l}9 \cdot 7 \\
9 \cdot 7\end{array}$ \\
\hline 5 & Liver & Two paraffin sections & $\begin{array}{l}\text { (a) Shikata orcein } \\
\text { (b) Haematoxylin/van Gieson }\end{array}$ & $\begin{array}{l}10 \cdot 1 \\
10 \cdot 4\end{array}$ & $\begin{array}{r}9 \cdot 8 \\
10 \cdot 6\end{array}$ \\
\hline 6 & Spinal cord & Block in formol saline & $\begin{array}{l}\text { (a) } \mathrm{H} \text { and } \mathrm{E} \\
\text { (b) Luxol fast blue }\end{array}$ & $\begin{array}{l}9.9 \\
9.4\end{array}$ & $\begin{array}{r}7.9 \\
8 \cdot 4\end{array}$ \\
\hline 7 & Kidney & Block in formol saline & $\begin{array}{l}\text { (a) } \mathrm{H} \text { and } \mathrm{E} \\
\text { (b) Congo red }\end{array}$ & $\begin{array}{l}10 \cdot 3 \\
10 \cdot 8\end{array}$ & $\begin{array}{l}9.9 \\
8 \cdot 7\end{array}$ \\
\hline 8 & Tongue & Block in formol saline & $\begin{array}{l}\text { (a) } \mathrm{H} \text { and } \mathrm{E} \\
\text { (b) Silver impregnation for axons }\end{array}$ & $\begin{array}{r}10 \cdot 9 \\
9 \cdot 2\end{array}$ & $\begin{array}{r}10 \cdot 1 \\
7 \cdot 9\end{array}$ \\
\hline 9 & Liver & Block in formol saline. & $\begin{array}{l}\text { (a) } \mathrm{H} \text { and } \mathrm{E} \\
\text { (b) Perls }\end{array}$ & $\begin{array}{l}10 \cdot 7 \\
11 \cdot 7\end{array}$ & $\begin{array}{l}9 \cdot 6 \\
9 \cdot 4\end{array}$ \\
\hline 10 & Kidney & Block in formol saline & $\begin{array}{l}\text { (a) } 2-3 \mu \mathrm{m} \text { paraffin section- }-\mathrm{H} \text { and } \mathrm{E} \\
\text { (b) } 2-3 \mu \mathrm{m} \text { paraffin section- } \\
\text { methenamine silver }\end{array}$ & $\begin{array}{r}10 \cdot 8 \\
8 \cdot 9\end{array}$ & $\begin{array}{r}10 \cdot 3 \\
8 \cdot 6\end{array}$ \\
\hline
\end{tabular}

Table 2 Material circulated for quality assessment and the group mean scores (second year of scheme)

\begin{tabular}{|c|c|c|c|c|c|}
\hline \multirow{2}{*}{$\begin{array}{l}\text { Circulation } \\
\text { No }\end{array}$} & \multirow[t]{2}{*}{ Tissue } & \multirow[t]{2}{*}{ Presentation } & \multirow[t]{2}{*}{ Request } & \multicolumn{2}{|c|}{ Group mean scores* } \\
\hline & & & & $\begin{array}{l}\text { North } \\
\text { Labs }\end{array}$ & $\begin{array}{l}\text { South } \\
\text { Labs }\end{array}$ \\
\hline 11 & Placenta & Block in formol saline & $\begin{array}{l}\text { (a) H and E } \\
\text { (b) MSB }\end{array}$ & $\begin{array}{r}13.2 \\
11.8 \\
9.1\end{array}$ & $\begin{array}{l}11.9 \\
11.5 \\
10.0\end{array}$ \\
\hline 12 & Lung & Block in formol saline & $\begin{array}{l}\text { (a) } \mathrm{H} \text { and } \mathrm{E} \\
\text { (b) } \mathrm{ZN}\end{array}$ & $\begin{array}{l}11.0 \\
11.4\end{array}$ & $\begin{array}{l}10 \cdot 6 \\
10 \cdot 8\end{array}$ \\
\hline 13 & Rib & Block in formol saline & (a) $\mathrm{H}$ and $\mathrm{E}$ & $\begin{array}{l}10 \cdot 8 \\
10 \cdot 1 \\
10 \cdot 3\end{array}$ & $\begin{array}{r}11 \cdot 1 \\
9.1 \\
11.5\end{array}$ \\
\hline 14 & Skin & Block in formol saline & $\begin{array}{l}\text { (b) Iron haematoxylin/van Gieson } \\
\text { (a) } \mathrm{H} \text { and } \mathrm{E}\end{array}$ & $\begin{array}{r}9.2 \\
11.3 \\
10.6\end{array}$ & $\begin{array}{l}10 \cdot 3 \\
11 \cdot 3 \\
11 \cdot 3\end{array}$ \\
\hline 15 & Colon & Block in formol saline & $\begin{array}{l}\text { (b) Argentaftin reaction for melanin } \\
\text { (a) } \mathrm{H} \text { and } \mathrm{E}\end{array}$ & $\begin{array}{r}9 \cdot 1 \\
10 \cdot 1 \\
10 \cdot 6\end{array}$ & $\begin{array}{r}9 \cdot 9 \\
10 \cdot 5 \\
11 \cdot 6\end{array}$ \\
\hline 16 & Prostatic curetting & Block in corrosive formol & $\begin{array}{l}\text { (b) Alcian blue } \\
\text { (a) } \mathrm{H} \text { and } \mathrm{E}\end{array}$ & $\begin{array}{l}10.8 \\
11.6 \\
10.8\end{array}$ & $\begin{array}{l}10 \cdot 6 \\
11.4 \\
11.0\end{array}$ \\
\hline 17 & Ovarian tumour & Block in formol saline & $\begin{array}{l}\text { (b) Trichrome } \\
\text { (a) } \mathrm{H} \text { and } \mathrm{E}\end{array}$ & $\begin{array}{r}9.7 \\
11.6 \\
11.0\end{array}$ & $\begin{array}{r}8.2 \\
11.6 \\
11.2\end{array}$ \\
\hline 18 & Small intestine & Block in formol saline & $\begin{array}{l}\text { (b) PAS } \\
\text { (a) } \mathrm{H} \text { and } \mathrm{E}\end{array}$ & $\begin{array}{l}11.3 \\
11.2 \\
11.0\end{array}$ & $\begin{array}{l}10 \cdot 3 \\
10 \cdot 8 \\
11 \cdot 2\end{array}$ \\
\hline 19 & Lung & Block in buffered formalin & $\begin{array}{l}\text { (b) Methyl green-pyronin } \\
\text { (a) } \mathrm{H} \text { and } \mathrm{E}\end{array}$ & $\begin{array}{r}9.0 \\
12.1 \\
11.5\end{array}$ & $\begin{array}{r}8.0 \\
12.0 \\
11.7\end{array}$ \\
\hline 20 & Heart & Block in buffered formalin & $\begin{array}{l}\text { (b) Elastic/van Gieson } \\
\text { (a) } \mathrm{H} \text { and } \mathrm{E}\end{array}$ & $\begin{array}{l}10.9 \\
11.8 \\
11.0\end{array}$ & $\begin{array}{l}10 \cdot 6 \\
11.6 \\
11.3\end{array}$ \\
\hline & & & (b) PTAH & 9.2 & 7.4 \\
\hline
\end{tabular}

*The first mean assessment for each $\mathrm{H}$ and $\mathrm{E}$ is for the technical aspects, the second is for the staining.

were divided into two equal groups, North and South, and were marked by separate panels of primary and control assessors. Each panel of primary assessors was chosen from one area, so that they could meet, assess the slides at one session, and return their individual assessments rapidly. Control assessors were chosen from among the participants in the scheme, and the material was circulated to them separately by post so that assessment took a considerable time. Each panel of assessors consisted of two pathologists and two MLSOs. All assessors were asked to mark each slide as if it was prepared for 
diagnostic use by a routine laboratory. If the slide was regarded as highly satisfactory 4 marks were given; if satisfactory 3 marks; if just adequate 2 marks; and if unsatisfactory 1 mark. Zero was used for failure to submit slides in time for assessment. The assessors were invited to comment on the performance and were asked particularly to give reasons for low marking. In the guidance, assessors were particularly asked not to allow personal preference about the intensity of eosin staining to affect the marks given.

During the second year of the scheme more precise guidance was given to the assessors and the assessment of each $\mathrm{H}$ and $\mathrm{E}$ was subdivided with marks being given separately for (i) processing, microtomy, and mounting, and (ii) staining only.

\section{REPORT ON PERFORMANCE}

A report was sent each month to the laboratories showing their aggregate scores (maximum 16 for each assessment), the monthly mean of their group of laboratories, the range of the scores and any comments made by the assessors on their slides. The group mean scores are shown in Tables 1 and 2 .

Annual reports to the participants gave a general analysis of each year's performance and showed the department's half-yearly mean scores, the means and ranges for the group and the number of slides received which were considered less than adequate (less than 8 marks). Each laboratory was informed of its position in the rank order of laboratories for each of the four half-yearly periods.

\section{FEEDBACK}

During the second year of the scheme the participating MLSOs and pathologists were asked to complete questionnaires. In addition to a common general section, the MLSOs were asked to complete a technical section.

\section{Results}

\section{ACCEPTABILITY}

Forty-two out of 46 laboratories approached (91\%) accepted the invitation to participate in the two-year scheme. None withdrew during the two-year period.

During the period of the scheme, $90 \cdot 1 \%$ of slides were submitted in time for assessment. The numbers arriving late brought the total response to $94 \cdot 1 \%$.

\section{ASSESSMENT}

The reproducibility and reliability of assessment was studied in a number of ways. Individual assessors were compared with the other assessors in the panel and each panel of primary assessors was compared with its control assessors. In addition, half way through the first year, the panels of primary assessors were switched so that they could be compared with a different panel of control assessors.

\section{Individual assessors}

Intragroup analysis was approached in two ways:

(a) The marks given by each assessor for each set of slides was compared with those given by his coassessors, and with the overall mean. An example of these results is shown in Table 3. Outstanding variationso are immediately apparent. The greatest intragroups variation occurred in the Giemsa-stained slides (cirô culation 3b). Assessor 1 was more severe in his marking than his colleagues, giving the lowest mark in 7 of the 10 instances shown.

(b) An alternative approach was to analyse each assessor's bias. The difference between the mark given by an assessor for each individual slide and the mean of the marks given by his coassessors was calculated. The mean and standard deviation of each assessor's bias was calculated for each group of slides.

Figures 1 and 2 show the bias means of the first and second year assessors. Each point represents the

Table 3 A comparison of individual assessor's marks

\begin{tabular}{|c|c|c|c|c|c|c|c|c|}
\hline \multirow{2}{*}{$\begin{array}{l}\text { Circulation } \\
\text { No }\end{array}$} & \multirow{2}{*}{$\begin{array}{l}\text { Total } \\
\text { possible } \\
\text { marks }\end{array}$} & \multicolumn{7}{|c|}{ Assessor's marks } \\
\hline & & $l^{*}$ & $2^{*}$ & $3^{*}$ & $4^{*}$ & Mean & $S D$ & $\begin{array}{l}\text { Coefficient } \\
\text { of variation }\end{array}$ \\
\hline $\begin{array}{l}1 \mathrm{a} \\
1 \mathrm{~b} \\
2 \mathrm{a} \\
2 \mathrm{~b} \\
3 \mathrm{a} \\
3 \mathrm{~b} \\
4 \mathrm{a} \\
4 \mathrm{~b} \\
5 \mathrm{a} \\
5 \mathrm{~b} \\
\text { Mean }\end{array}$ & $\begin{array}{l}68 \\
68 \\
64 \\
64 \\
76 \\
76 \\
76 \\
72 \\
76 \\
76\end{array}$ & $\begin{array}{l}44 \\
43 \\
40 \\
42 \\
48 \\
33 \\
38 \\
39 \\
44 \\
48 \\
41 \cdot 9\end{array}$ & $\begin{array}{l}48 \\
44 \\
45 \\
42 \\
51 \\
47 \\
45 \\
41 \\
46 \\
51 \\
46\end{array}$ & $\begin{array}{l}44 \\
42 \\
42 \\
44 \\
48 \\
48 \\
50 \\
48 \\
54 \\
51 \\
47 \cdot 1\end{array}$ & $\begin{array}{l}45 \\
43 \\
38 \\
39 \\
52 \\
51 \\
52 \\
47 \\
46 \\
51 \\
46 \cdot 4\end{array}$ & $\begin{array}{l}42 \cdot 25 \\
43 \cdot 00 \\
41 \cdot 25 \\
41 \cdot 75 \\
48 \cdot 75 \\
44 \cdot 75 \\
46 \cdot 25 \\
43 \cdot 75 \\
47 \cdot 50 \\
50 \cdot 25 \\
45 \cdot 35\end{array}$ & $\begin{array}{l}1 \cdot 6 \\
0.7 \\
2.6 \\
1.8 \\
1 \cdot 8 \\
6 \cdot 9 \\
5 \cdot 4 \\
3 \cdot 8 \\
3 \cdot 8 \\
1 \cdot 3 \\
2 \cdot 0\end{array}$ & $\begin{array}{r}3 \cdot 5 \\
1 \cdot 6 \\
6 \cdot 3 \\
4 \cdot 3 \\
3 \cdot 6 \\
15 \cdot 4 \\
11 \cdot 7 \\
8 \cdot 7 \\
8 \cdot 0 \\
5 \cdot 0 \\
4 \cdot 4\end{array}$ \\
\hline
\end{tabular}

${ }^{*}$ Code no of individual assessor. 


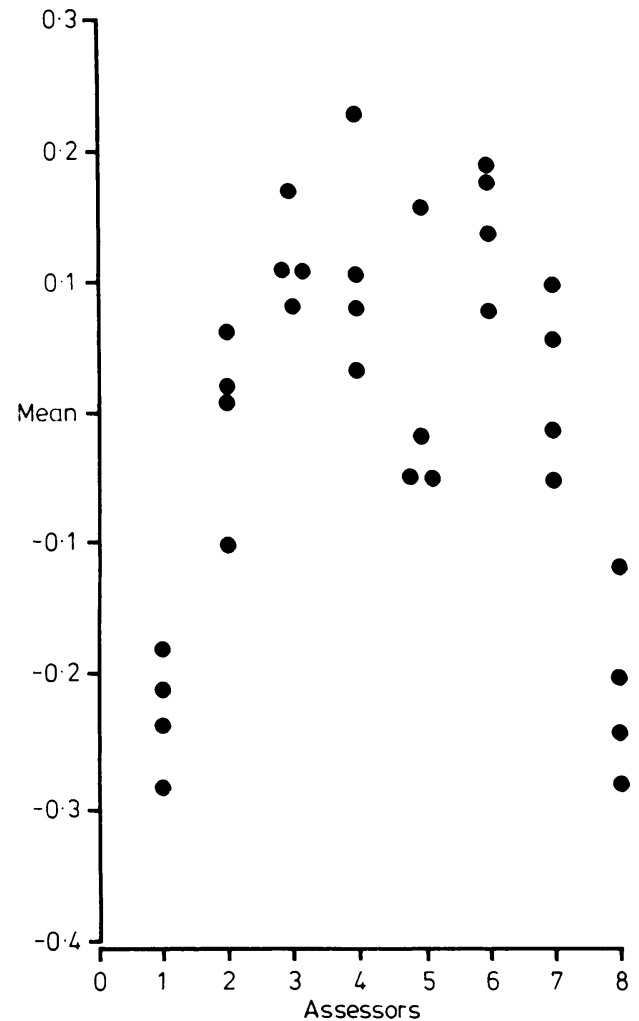

Fig. 1 Bias of individual assessors (first year of scheme). Each point represents the mean bias of an individual assessor as compared to the mean of his three coassessors on a set of slides circulated during a five-month period (90-94 assessments per point).

mean bias of the assessments on a five-month group of slides, ( $\mathrm{H}$ and $\mathrm{E}$ and special stains being considered separately for Fig. 1, and the subdivision of $\mathrm{H}$ and $\mathrm{E}$ marking being considered separately for Fig. 2 ). There were more than 90 slides in each group. It can be seen from Figs. 1 and 2 that there was considerable variation in bias between assessors but each assessor showed reasonable internal consistency. It should be remembered that the marking advice and system differed between the first and second year of the scheme.

\section{Panels of assessors}

Analysis of the primary and control assessments was carried out in two ways:

(a) The mean marks given by each panel of primary assessors were compared with the mean marks given by the control assessors, for the same set of slides. These results are presented graphically in Fig. 3, (a-d). each figure showing the results from a half yearly period. With occasional exceptions, a remarkable degree of agreement is seen in $a, b$ and c, whilst in $\mathrm{d}$ a consistent bias is well illustrated.

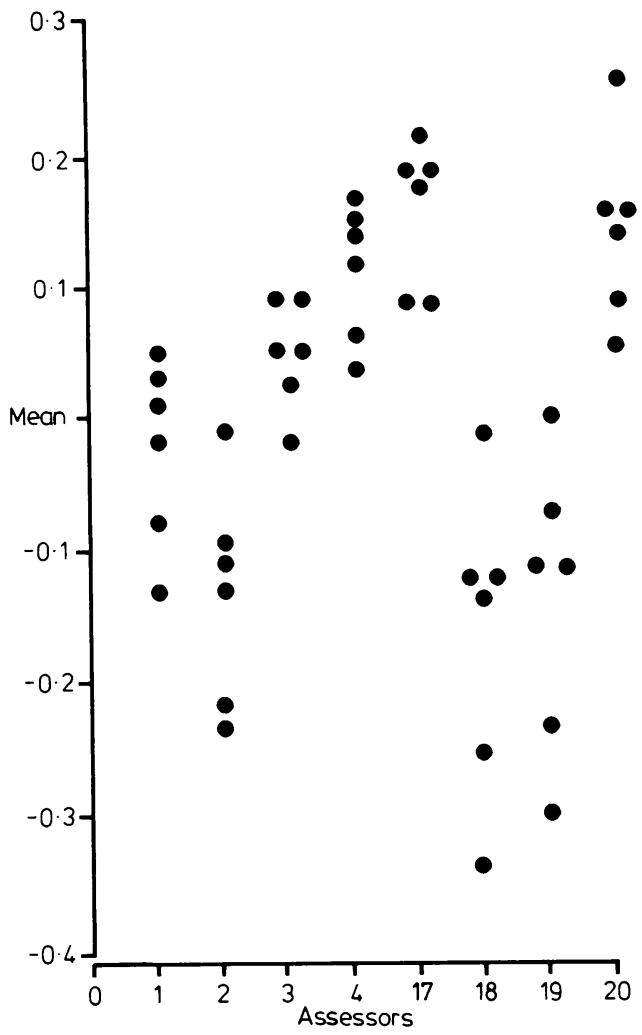

Fig. 2 Bias of individual assessors (second year of scheme). Each point represents the mean bias of an individual assessor as compared to the mean of his three coassessors on a set of slides circulated during a five-month period (90-94 assessments per point).

(b) A regression analysis was carried out on the scores given for each slide by the primary and by the control assessors. The first year's slides were analysed in eight groups each containing 89-95 slides. For each of the eight groups the correlation was found to be highly significant (Table 4).

\section{Re-assessment}

One panel of assessors was asked to repeat the assessment on one group of slides from the first year, adopting both the old and the new methods for the $\mathrm{H}$ and E slides.

Of the $\mathrm{H}$ and $\mathrm{E}$ slides, $62 \%$ were given the same individual mark, no slide was more than one mark away from the original score. In $88 \%$ of the $\mathrm{H}$ and $\mathrm{E}$ slides and in $75 \%$ of the special slides the total mark given was the same or within one mark of the original total assessment (range 4-16 marks). In all, 33 slides were reassessed by the same panel of assessors, regression analysis showed a highly significant correlation between the original and the repeat assessments $(r=0.729 ; p<0.001)$. 


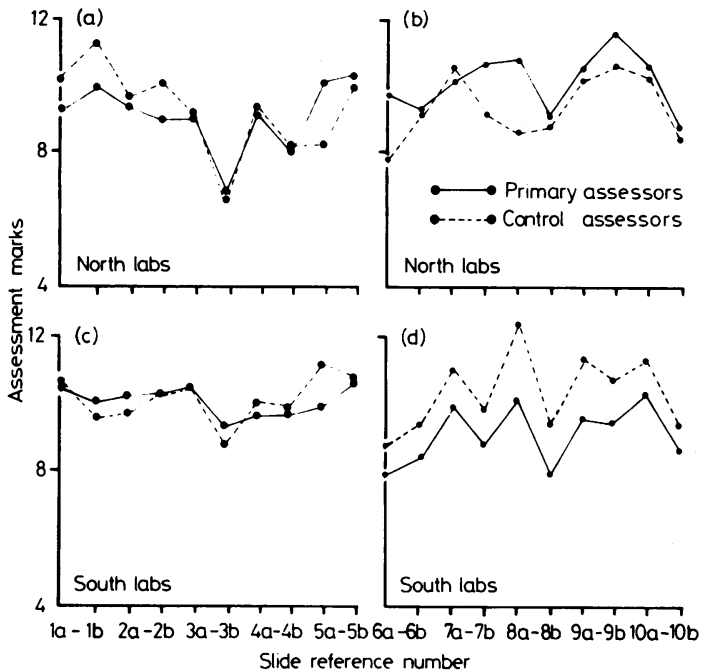

Fig. 3 (a-d) Comparison of primary and control panels of assessors. Each point represents the mean mark given by the panel to a monthly group of approximately 20 slides. The primary panel of assessors serving the South laboratories during the first half-year served the North laboratories during the second half-year and vice versa.

\section{Comparison of assessment by MLSOs and pathologists}

Over the two years the mean assessment of all slides by MLSOs was 10.56 whilst that of pathologists was $10 \cdot 30$.

\section{LABORATORY PERFORMANCE}

The total number of marks given by a panel of assessors to an individual section ranged from 4 to 16 , although the extremes were infrequent. If the relatively small number of slides not returned is ignored, the mean mark given to each laboratory over a halfyear period ranged from $7 \cdot 2$ to $12 \cdot 6.11 \cdot 9 \%$ of slides were given assessments of less than 8 , and were therefore considered less than adequate.

While laboratory performance varied considerably from circulation to circulation, there was reasonable consistency in the overall assessment of laboratory

Table 4 Regression analysis of primary and control assessments

\begin{tabular}{lllll}
\hline Slide groups & Laboratories & $n$ & $r$ & $p$ \\
\hline 1a-5a & South & 90 & 0.803 & $<0.001$ \\
& North & 89 & 0.543 & $<0.001$ \\
1b-5b & South & 89 & 0.691 & $<0.001$ \\
& North & 90 & 0.697 & $<0.001$ \\
6a-10a & South & 95 & 0.714 & $<0.001$ \\
& North & 92 & 0.524 & $<0.001$ \\
6b-10b & South & 92 & 0.619 & $<0.001$ \\
& North & 91 & 0.764 & $<0.001$ \\
\hline
\end{tabular}

performance. Marking only on the basis of slides submitted, and considering the results from north laboratories over four five-monthly periods, one laboratory was present among the top five in rank order on all four occasions, two laboratories on three occasions and one laboratory on two occasions. Among the bottom five in rank order, two laboratories were present on each of the four possible occasions and two were present on three occasions. There was also an interesting relation between the failure to return slides in time for assessment and the mark given to slides that were returned. The two laboratories which failed to return the largest number of slides were among the three lowest overall laboratories in rank order of mean marks given to returned slides.

\section{QUESTIONNAIRE}

Ninety per cent of MLSOs and 79\% of pathologists returned completed questionnaires. A majority of participants considered the scheme to be of value (MLSOs 76\%, pathologists 85\%). A more detailed analysis of the participants' assessment of the value of the scheme is shown in Table 5.

An analysis of the most commonly requested staining techniques was made in order to ensure that these had been or would be included in the scheme. Each laboratory was asked to list its 10 most com-monly performed special stains. The overall "top ten" are shown in Table 6 in order of frequency. All

Table 5 Assessment of the values of external quality assessment

\begin{tabular}{lll}
\hline Value & \multicolumn{2}{l}{ Profession $^{*}$} \\
\cline { 2 - 3 } \cline { 2 - 3 } & $\begin{array}{l}\text { MLSO } \\
\%\end{array}$ & $\begin{array}{l}\text { Path } \\
\%\end{array}$ \\
\hline Increasing an awareness of quality & 84 & 82 \\
Improving standards & 74 & 70 \\
Providing material for education & 55 & 42 \\
Improving accuracy of diagnosis & 29 & 24 \\
Assessing efficacy of staining methods & 61 & 61 \\
Assessing staining materials & 61 & 58
\end{tabular}

*The results are the percentages of those participants completing the questionnaire who answered "yes."

Table 6 Most frequently requested staining techniques*

Reticulin

Perls

Periodic acid-Schiff

Elastic

Ziehl-Neelsen

van Gieson

Gram

Masson-Fontana

Alcian blue

Trichrome

*The figure quoted is the number of departments (of 38 replies) who placed the technique in their first ten. 
have been included in the pilot scheme with the exception of Gram stain.

An analysis of the performance of the laboratories with respect to total work load and to requests per MLSO was made; there was no correlation in either case.

Most of the general comments on the scheme were favourable. There were a few specific objections to the scheme but the majority of the adverse comments related to requests for more detailed reasons from the assessors to explain low marks.

\section{Discussion}

The major criticisms of EQA schemes in histopathology are that they are unnecessary, unworkable, and inaccurate. The major difference between histopathology and other pathology disciplines lies in the subjective nature of the assessment, and one of the major purposes of this investigation was to test whether assessment of the technical aspects of a section could be reliable. We have shown that when assessors were asked to mark slides on their acceptability for diagnosis, there was a considerable difference in the marking standards applied by different assessors. This was true both when the assessors were asked to consider the preparation as a whole, and when they were asked to mark staining separately from earlier procedures. The differences were not surprising, but they were considerable, and must be taken into account in the application of any such scheme. We have also found, however, a high degree of consistency in the standards applied by assessors, both in their performance relative to one another, and in the reproducibility of individual assessments when repeated on the same slides over a year later. This suggests that the relative standard of preparation can be assessed with acceptable accuracy, but that in this pilot scheme, for changes in the marks given to any one laboratory over a period of time to be meaningful, the same assessors and the same marking system should be used. We believe that this difficulty could be largely overcome in any future scheme by including in each batch marked by the assessors a group of slides from a previous assessment of the same stain carried out on the same tissue, and comparing the two sets of marks. This would only be possible in an EQA scheme that ran for a number of years, but we believe it would allow assessment of absolute as well as relative change in a laboratory's performance.

The marking scale we adopted has proved easy to apply, although arguments could be put forward for expanding or contracting it. To mark a slide only as acceptable or not acceptable would simplify marking still further, but we believe that the inability to rec- ognise the outstanding slide, as well as the lack of separation between a good and a just adequate preparation would be a considerable loss; and would not help to maintain high standards in the laboratory. The demand from the participating laboratories was, as shown by the questionnaire, for more, not less, detailed marking.

One common criticism of histopathology EQA schemes is that the material returned has been specially treated, and is therefore not representative of the laboratories' routine output. All of the replies to the questionnaire stated that the test material was treated as routine; all laboratories used automatic processors. A minority, while claiming to treat them as routine, did in fact ensure that all staff in the department in turn performed the microtomy on the test blocks. In the majority of departments $\mathrm{H}$ and $\mathrm{E}$ staining was carried out automatically, both for routine and test sections; in only one department were the test special stains always carried out by one selected member of staff.

The evidence therefore suggests that in the great majority of instances the test material was not specially treated. Even if a much greater proportion were specially treated we do not believe that this would invalidate the scheme, as one of the most valuable uses of a scheme such as this is to provide an independent yardstick against which a department can measure its own standards. The responsibility for maintaining standards rests on a department, and the general standard in the UK is, we believe, high. In all departments who replied to the questionnaire, the results were discussed with the technical staff concerned, and in the great majority of the departments, with the pathologist also.

As well as providing an objective standard against which a department can measure its technical attainment, this scheme has a number of other benefits. It asks the laboratories to perform a wide range of special stains and provides them with a wide range of material which may not always be available to them otherwise. It provides information which can help to determine whether differences in performance of certain stains is due to batch variation, and it provides a sense of participation at a national level that may be particularly important to small or isolated laboratories.

In the United Kingdom national EQA schemes operate for all major pathology disciplines, except histopathology; the operation of these schemes has recently been reviewed ${ }^{2}$ and a Welsh EQA scheme in histopathology, previously described ${ }^{1}$ has now been running successfully for five years. Internationally we know of schemes in development or in progress in the USA, Australia and Ireland. A World Health Organisation working group has recently dis- 
cussed the whole background of EQA schemes and recommends their extension. ${ }^{3}$

In the United Kingdom we believe that a nationwide scheme for histopathology, organised only from one centre, would pose considerable logistic problems, both because of the difficulties of providing uniformity of material and because of the difficulties of marking. Having experienced the practical problems involved in running a scheme for 42 laboratories, we believe that the best solution would be to organise a network of regional schemes, and involve participating laboratories in assessment. This not only reduces the understandable concern about central control, but also increases the feeling of involvement, and broadens the experience of the staff concerned. It also means that a central laboratory is not required, and the additional work load for the department asked to run the regional scheme is not great. The most important need would be for a part time confidential secretary in each of the centres.

We have shown in this pilot scheme that assessment of technical quality of histopathology sections can be made sufficiently accurate and reproducible for use in an EQA scheme in histopathology. We have shown that such a scheme can be organised efficiently for a group of about 40 laboratories, and that it is in general endorsed by the participating laboratories. At the start of this discussion we commented that the main criticisms of EQA schemes in histopathology were that they were unnecessary, unworkable, and inaccurate. We have now shown that they can be made workable and accurate. There is no doubt that they can be acceptable, and we believe they are necessary.

We are grateful for the expert secretarial assistance of Mrs J Bishop (supported by the DHSS) and Mrs W Williams. The successful completion of the scheme would not have been possible without the cooperation of the 20 assessors who dedicated much of their time to the task of assessment. Our thanks are due to the 42 pathologists who agreed to participate and to the 42 MLSOs who subjected the work of their departments to the assessors' scrutiny and received adverse comments almost without complaint.

We would like to thank the DHSS for supporting the scheme financially, so allowing us to pursue the possibility of the development of the Welsh Scheme into an EQA scheme for England, Dr FP Woodford of the DHSS for his advice, interest and encouragement, and both the Royal College of Pathologists and the Institute of Medical Laboratory Sciences for their support.

\section{References}

${ }^{1}$ Barr WT. Technical quality control in histopathology.J Clin Pathol 1978;31:996-8.

2 Whitehead TP, Woodford FP. External quality assessment of clinical laboratories in the United Kingdom. J Clin Patholo 1981;34:947-57.

${ }^{3}$ External Quality Assessment of Health Laboratories, EURO Reports and Studies No 36. Copenhagen: WHO Regional? Office for Europe, 1981.

Requests for reprints to: Mr WT Barr, Histopathology Department, University Hospital of Wales, Heath Park, Cardiff, S Wales CF4 4XW. 